\title{
O USO DE FERRAMENTAS DA INTERNET NO ENSINO DE LÍNGUA INGLESA E SEUS REFLEXOS NA INCLUSÃO SOCIAL DE ALUNOS DE ESCOLAS PÚBLICAS
}

Lucas Araujo Chagas/Universidade Federal de Uberlândia

RESUMO: Nas últimas décadas, juntamente com a consolidação da língua inglesa como língua franca, novas tecnologias começaram a ganhar espaço no seu ensino/aprendizagem. Estas possibilitaram incrementar o processo de ensino de línguas estrangeiras e aproximá-lo às exigências de constante atualização e modernização da sociedade atual. Nesse contexto, a internet emerge como uma ferramenta indispensável no que diz respeito à pesquisa e ao contato com saberes pertinentes aos conteúdos trabalhados na escola. Neste trabalho, apresentaremos meios de conciliar a internet e o ensino de língua inglesa, de forma a promover a inclusão social de alunos de escolas públicas.

PALAVRAS-CHAVE: Ensino/aprendizagem. Língua inglesa. Internet. Inclusão social. Escolas públicas.

\begin{abstract}
In the last decades, together with the growth of the English language as the lingua franca, new technologies started to gain space in the teaching/learning of the language. These made it possible to improve the teaching/learning process and meet the demands for constant updating and modernization of current society. In this context, the internet has gained space and today it has become an essential tool regarding research and contact with school knowledge. In this study we present ways to bring together the internet and the teaching of English in order to promote the social inclusion of public school students.
\end{abstract}

KEYWORDS: Teaching/learning. English Language. Internet. Social inclusion. Public schools.

\section{INTRODUÇÃO}

Em virtude do desenvolvimento científico e comercial nos últimos anos, da globalização da economia mundial e da quebra das fronteiras internacionais, a necessidade de se aprender uma segunda língua ou uma língua estrangeira tem ganhado cada vez mais espaço na comunidade internacional. Como exemplo, podemos citar a língua inglesa que, após a Segunda Guerra Mundial, passou a ser fundamental para firmar acordos e promover a intercomunicação cultural, científica, intelectual e social no mundo.

Tal demanda no aprendizado do inglês como língua estrangeira (LE) ou como segunda língua deve-se não só a fatores comerciais e científicos, mas ao fato de políticas educacionais recentes colocarem grande ênfase no ensino do inglês como um dos conhecimentos constituintes da educação básica, juntamente com o letramento na língua materna ou oficial, habilidades 
matemáticas e o letramento computacional (MOITA LOPES, 2008).

Nas últimas décadas, adjacente à consolidação da língua inglesa como língua franca, novas tecnologias começaram a ganhar espaço no seu ensino/aprendizagem. Estas, de certa forma, possibilitaram incrementar o processo de ensino de línguas estrangeiras e aproximá-lo às exigências de constante atualização e modernização da sociedade atual.

A utilização de novas tecnologias no ensino de línguas, de um modo geral, tem repercutido nos mais variados setores educacionais. Nesse contexto, professores e pesquisadores investigam meios de conciliar tecnologia e ensino, de forma a torná-la parte dos recursos pedagógicos utilizados em sala de aula. Entre as ferramentas disponíveis no cabedal das novas tecnologias, a internet se destaca por estar presente não só em sala de aula, mas por ser de livre acesso em diversos ambientes sociais.

Apesar de Políticas Educacionais Brasileiras colocarem importância na necessidade de inserir as novas tecnologias no ensino de língua inglesa, sabemos que a realidade circunstancial escolar de vários estados brasileiros ainda é perpassada pela não- aplicação dessas políticas.

Neste artigo, procuraremos investigar como a utilização de algumas ferramentas triviais da internet podem ser usadas dentro de sala de aula de língua inglesa, de forma a contribuir com a inclusão social de alunos de escolas públicas. Inicialmente problematizaremos o conceito de inclusão, especificamente inclusão social, que norteará a nossa pesquisa; em seguida, falaremos da metodologia de pesquisa que utilizamos; delinearemos de que forma a relação das novas tecnologias com o aprendizado de língua inglesa pode resultar na inclusão social dos alunos de uma escola pública; e, por fim, concluiremos com algumas ponderações sobre o papel do professor como árbitro do uso das tecnologias virtuais em sala de aula.

\section{CONCEITO(S) DE INCLUSÃO SOCIAL}

A palavra "inclusão" pode ser utilizada para denominar diversas ações pelas quais um grupo social contém ou inclui o outro. Constantemente, o ato ou ação de incluir tem repercutido em políticas sociais e públicas em diversas partes do mundo. Ao enumerarmos usos da palavra “inclusão” na atualidade, podemos apontar, por exemplo, a inclusão de deficientes, inclusão racial, inclusão digital, inclusão social, inclusão monetária, dentre outros.

Apesar das diversas modalidades de inclusão, quando falamos em políticas educacionais brasileiras, é preciso lembrar que, nos últimos anos, elas têm atribuído à escola a função de educar, consolidar a implantação de novos valores na sociedade e até mesmo promover o que elas denominam de formação social. Por outro lado, apesar de a escola procurar, em certa medida, refletir o seu conceito de organização e, como tal, estabelecer uma hierarquia definida, onde o poder infiltra-se de cima para baixo através do corpo docente até chegar aos alunos, (FRIEDMAN, 1977) observa-se que a sociedade na qual se inserem os sujeitos aprendizes tem valores culturais, morais e sociais próprios.

No Brasil, percebe-se que a relação entre aluno e professor ainda é marcada por posicionamentos fixos, em que o aluno encontra-se como desprovido de maturidade diante de um sistema de normas e valores que lhe é imposto pela figura autoritária do professor.

Em uma pesquisa realizada no ano de 2007 pela Revista “Nova Escola” (2009) e pelo 
Instituto Brasileiro de Opinião Pública e Estatística - IBOPE - com 500 professores de todo o país, foi constatado que 69\% deles apontavam a indisciplina e a falta de atenção entre os principais problemas da sala de aula. Em uma reportagem, a revista on-line "Educar Para Crescer” (2009), que fez referência a tal pesquisa, começa seu texto da seguinte maneira:

\begin{abstract}
A garotada voa pelos corredores, conversa em sala, briga no recreio, insiste em usar boné e em trazer para a sala materiais que não são os de estudo. A paciência do professor está por um fio. Cansado e confuso, ele se sente com os braços atados e a autoridade abalada. Não suporta mais as cenas que vê e não sabe o que fazer. Quer obediência! Quer controle! Quer mudanças no comportamento dos alunos! (VICHESSI, 2009, s/p).
\end{abstract}

Nesse excerto, percebe-se, de uma forma geral, a tradicional demarcação de posicionamentos estabelecidos ou exigidos pelo professor, que quer "obediência”, "controle" e "mudanças no comportamento dos alunos". Ainda, na frase "insiste em usar boné e trazer para a sala materiais que não são os de estudo”, observa-se, com clareza, que a escola procura reforçar sua hierarquia estabelecida, responsável por preparar e disciplinar os alunos para o convívio social.

Como se a disciplina fosse suficiente para promover o bom desenvolvimento escolar e agregar conhecimento aos alunos, nos discursos educacionais mais recentes frequentemente encontramos professores apontando a falta de disciplina como a causa para o caos escolar que grande parte das escolas tem vivido. Por outro lado, podemos considerar que a indisciplina nasce dessa diferença valorativa exigida pela escola e pelo sistema educacional em relação aos alunos, visto que a sociedade em que eles estão imersos tem valores culturais, morais e sociais próprios já arraigados. Sendo assim, o aluno, ao entrar para a escola, não está desprovido de maturidade; pelo contrário, ele traz consigo valores culturais, morais e sociais que certamente entrarão em conflito com o atual aprisionamento exercido pela escola - em especial as escolas públicas estaduais expresso não apenas pela sua estrutura física, como também pela própria sistemática escolar da atualidade.

Muitas vezes, os valores e normas exigidos pela escola figuram apenas dentro do ambiente escolar e fazem pouco sentido para o aluno. Isso ocorre em virtude da resistência do aluno em acatar e apropriar-se de valores e conhecimentos que, muitas vezes, não têm relevância para seu contexto social e seus interesses pessoais. Dessa forma, as funções atribuídas à escola passam a ser meramente estanques, visto que o que ali dentro se aprende, ali é retido. Não queremos dizer que a disciplina seja desnecessária, contudo, o que nos cabe aqui é questionar como alguns valores educacionais são impostos e os resultados que se efetivam através deles.

Quando analisamos os desencontros entre a existência e a prática de políticas que visam à inclusão social, mas não levam em consideração a hibridez cultural da sociedade brasileira e dos indivíduos envolvidos no ambiente educacional, percebemos que, de um modo muito amplo, elas acabam agregando à escola um caráter exclusivo, e não inclusivo. Isso porque, muitas vezes, a inclusão social é concebida, em alguns discursos, não como uma questão educacional, mas como uma questão de padrão moral, hierárquico e social pré-estabelecido por culturas dominantes ${ }^{i}$.

Monte Mór \& Menezes de Souza (2006), ao analisarem o conceito de inclusão e exclusão de um cidadão, propuseram que eles vão muito além do âmbito escolar e repercutem em toda uma sociedade. Assim sendo, Monte Mór \& Menezes de Souza (2006) propõem que, ao contrário da inclusão, a exclusão serve para se referir a ações e/ou situações características de desigualdades sociais e econômicas que vão contra o padrão social de desenvolvimento humano. Igualmente, a exclusão também diz respeito aos meninos de rua, à violência e demais fatores, dentro 
e fora da escola e das redes de significados nos meios sócio-político-culturais. Desse modo, se a escola não se preocupar em desenvolver a inclusão social de alunos, contribuirá para reforçar as desigualdades sociais que caracterizam situações de exclusão.

Tendo-se conhecimento dos efeitos provocados pela exclusão, deduz-se que a inclusão social, da forma como a concebemos neste trabalho, pode propiciar aos alunos o reconhecimento da heterogeneidade característica das linguagens, saberes e culturas do contexto social no qual estão inseridos. Tal reconhecimento pode contribuir para o questionamento de verdades tidas como fixas, únicas e estáveis.

Sendo a escola uma instituição pluridisciplinar e formada por diferentes pessoas, a função de incluir socialmente deveria acontecer partindo da perspectiva que discutimos acima, ou seja, ela deveria promover a interação entre conhecimento e sociedade, fazendo com que essa relação se reflita no comportamento e nas ações do cidadão e em seu convívio social (SOUZA \& MONTE MÓR, 2008).

Querer adestrar alunos a uma realidade social diferente da sua parece negar todo o conhecimento que eles trazem do seu convívio social, que pode ser aproveitado e compartilhado dentro e fora de sala de aula. Por outro lado, quando promovemos a interação entre sociedade e conhecimento, a partir do questionamento de crenças e fatores já arraigados na realidade social próxima dos alunos, novos paradigmas vão sendo instaurados. Assim, a instauração desses novos paradigmas passa a alterar gradativamente as perspectivas comportamentais, históricas e educacionais dos sujeitos e das comunidades que as experimentam (KUHN, 2008), o que pode ser um instrumento capaz de conduzir os alunos - a longo prazo - a ocuparem esferas sociais e reflexivas consideradas "desenvolvidas" e "inclusas".

\section{A INTERNET E A LÍNGUA INGLESA EM PROL DA INCLUSÃO SOCIAL}

Até agora problematizamos a inclusão social a partir de uma perspectiva escolar ampla e generalizada. De outro modo, nesta parte esperamos direcionar essas reflexões à inclusão social no seu âmbito digital e linguístico (Língua Inglesa).

Antes de realizarmos a nossa pesquisa, visitamos várias escolas nas regiões do Triângulo Mineiro e Alto Paranaíba (Minas Gerais). O intuito dessas visitas era selecionar uma escola pública que dispusesse de um laboratório de informática com acesso à internet e que oferecesse condições favoráveis à realização da pesquisa. Em um lembrete afixado no laboratório de informática de uma escola estadual (2012) da cidade de Patrocínio - MG liam-se as seguintes frases: 


\section{REGRAS GERAIS DE USO DO LABORATÓRIO DE INFORMÁTICA \\ - É terminantemente proibjido acessar piginas de relacionamento pessoal (Facebeok, Orkut, Yaheogroups. Blogs, stc) nas dependéncias deste laboratorio. \\ - Os emalls pessoais só deverào ser acessa dos pelos alunos nos horanios permitidos pelo professor instrutor \\ - Durante as aulas de informática os alunos devem fazer apenas o que é pedido pelo professor instrutor. \\ - Aqui se aplicam as mesmas regas de vestuario da escola. Nio é permitido o uso de boné ou toucas, homens utilizarem brincos e sderecos; piercing de todos os tipos; cabelos coloridos de cores extravagantes, sorte e ou penteado que fuja do habitual; uso de chinclo e sandalias abeatas; calca pescador, guixiquss, sigarete, mini-saia, bemudas, decotes, etc5 descer as escadas conendo, gritando, fazendo uso de palavras inadequadas ao ambiente estudantil; uso de celular, iPed e aparelhos eletrónicos. \\ 9S ALUNOS QUE DESACATAREM AS NORMAS DEFINTAS PELA DIREÇ̃o DA ESCOLA RECEBERIO ADVERTENCLA E DEVIDAS PUNICÖES! \\ (Dizeres literalmente copiados de umlembrete espalhado nas quatro paredes do laboratónio de informática da Escola Estadual Joāo de Deus*.) \\ Nome fortzriadaercola}

Figura 1: lembrete afixado no laboratório de informática de uma escola estadual (2012) da cidade de Patrocínio - MG

Ao analisarmos os dizeres do lembrete supracitado, percebemos de forma incisiva a demarcação de posicionamentos estabelecidos ou exigidos pela escola no que diz respeito ao comportamento dos alunos em seu interior. Percebemos também uma lógica de "escola como reprodução de saberes” na frase "Durante as aulas de informática os alunos devem fazer apenas o que é pedido pelo professor instrutor”.

A proibição do acesso às páginas de relacionamento (Facebook, Orkut, Yahoogroups, blogs, etc) é algo que abre nossos olhares para um posicionamento adestrador da escola em relação às práticas sociais dos alunos. É consenso dizer que, não só os alunos das escolas públicas do Brasil, mas grande parte dos brasileiros gastam um bom tempo das horas em que estão conectados na internet em páginas de relacionamento, e que ali compartilham, na maioria das vezes, informações pessoais e corriqueiras de suas vidas ou comunidades. Aqui, percebemos que a negação desses veículos de comunicação e relacionamento como um possível ponto de partida para a construção de saberes e desenvolvimento de competências pode ser entendido como uma forma de contribuir para a exclusão social.

Acreditamos que esse caráter proibidor, expresso nos dizeres pedagógicos do fragmento acima, tem fechado os olhos dos alunos, ao invés de conduzi-los a uma reflexão crítica sobre as suas práticas sociais, de forma a expandi-las para o que é esperado dos cidadãos em uma sociedade global. O simples fato de usar as páginas de relacionamento pessoal acessadas cotidianamente pelos alunos para o acesso a informação e incremento dos conteúdos abordados dentro da escola seria, talvez, um grande passo para o que chamamos de "reflexos ou emergir de uma inclusão social dos alunos das escolas públicas”.

Quando falamos da realização da disciplina de língua inglesa na maioria das escolas públicas brasileiras, encontramos uma realidade que, embora seja diferente da encontrada no laboratório de informática da Escola Estadual João de Deus, aproxima-se do que chamamos de escola como "reprodução de saberes". Durante as nossas visitas às escolas, foi comum encontrarmos professores de exatas ministrando a disciplina de inglês. O que era mais problemático 
é que muitos desses nem sequer sabiam a língua inglesa e falavam abertamente que pediam aos alunos para traduzirem os textos do livro e muitas vezes nem corrigiam esses textos por falta de conhecimento da língua. Não sabemos quais são os critérios de seleção da Superintendência Regional de Educação para liberar a ocupação desses cargos a profissionais julgados por nós completamente desqualificados. Todavia, essa é uma problemática interessante a ser levantada, pois muitas vezes nós, professores de inglês, arcamos com consequências que não são provocadas por nós, mas em instâncias que nos governam.

De acordo com dados do Conselho Britânico de 2013 (www.weforum.org), estima-se que mais de 1,7 bilhão de pessoas está aprendendo inglês (LE), o que o caracteriza como a língua estrangeira mais estudada no mundo. As projeções do Conselho dizem que, se o crescimento do inglês como língua franca continuar no mesmo ritmo, até 2020 ele terá mais de 3,8 bilhões de falantes - nativos e não nativos. Ainda, segundo Graddol (2006), mesmo com a presença de outras línguas na internet, o inglês ainda é responsável por 68\% da troca de informações que ocorrem via internet e domina todo o conteúdo de 32\% de todos os sites da WEB.

Ao tomarmos ciência de que o inglês é possivelmente a única língua estrangeira até hoje que possui mais falantes não-nativos do que nativos, somos capazes de refletir sobre o seu aspecto interlocutor de culturas e povos. Tal função possibilita a quem domina a língua inglesa estar em contato com os mais variados saberes produzidos em esferas globais e locais. Ao refletirmos sobre as condições de oferta da língua inglesa nas escolas públicas logo acima e seu contraste com essas informações, podemos perceber que ela tem sido de caráter excludente e não de inclusão social.

Muito tem sido discutido a respeito de promover a interdisciplinaridade, a transdisciplinaridade e a transversalidade nos programas e parâmetros curriculares educacionais, já que elas abarcam a expansão da compreensão de mundo e a inclusão social de um indivíduo. Dessa forma, a educação seria voltada a ensinar os alunos a entenderem as relações entre as disciplinas escolares e a conexão delas com a realidade vivida por eles. O resultado esperado desse processo deve possibilitar a utilização do conhecimento para a compreensão da complexidade social em que vivem os cidadãos, caracterizada pelo hibridismo constitutivo de linguagens, de identidades e de culturas (COPE \& KALANTZIS, 2003).

Ao direcionarmos a interdisciplinaridade à aprendizagem de inglês como língua estrangeira, notamos que o processo resultante dessa ação deve ir muito além do caráter limitador da noção de "alfabetização" que até os anos 70 considerava o indivíduo apenas como consumidor da linguagem, e que ainda hoje permeia a realidade do ensino de línguas nas escolas regulares do Brasil. A problemática maior é exatamente a indisponibilidade do Estado, professores e sistema educacional para deslocarem essa forma "arcaica” de conceber a linguagem em seu contexto de ensino.

Segundo Moita Lopes (2008), se analisarmos as diferentes funções que o inglês e a internet exercem, hoje, sobre a humanidade, devido aos seus alcances globais, veremos que por meio desta última pode-se ter acesso a outros discursos sobre o mundo e sobre quem somos ou podemos ser, sendo ela, portanto, um veículo para construir uma outra globalização com base nos interesses de seus falantes, cujo hibridismo identitário (MENEZES DE SOUZA, 2004) deve ser levado em conta durante o planejamento e a execução de ações pedagógicas. Isso reforça a importância de adotarmos concepções de letramento, enquanto práxis social crítica e, juntamente com isso, reavaliarmos o ensino da língua inglesa na prática da interdisciplinaridade, reforçando as concepções de letramento.

Por se tratar de um recurso midiático disponível na grande maioria dos países, e por ser 
cada vez mais utilizada para executar tarefas do dia a dia voltadas para o bem público - como, por exemplo, pesquisar rotas e trajetos, informar-se sobre o clima, pagar impostos, marcar horário de atendimento em órgãos federais, fazer compras, etc, - a internet pode ser utilizada de várias maneiras para promover a inclusão social. Colocar o aluno em contato com os mecanismos disponíveis na web faz com que ele seja apresentado a novas práticas sociais que se voltam para o seu bem-estar social e para a construção da cidadania.

Quando falamos de educação, a internet exerce um papel fundamental no que diz respeito à pesquisa e ao aprofundamento de conteúdos trabalhados na escola. Em outras palavras, a internet, hoje, possibilita o acesso instantâneo a qualquer tipo de informação, em qualquer idioma, e de qualquer região do mundo em segundos. Essas informações, além de se acrescentarem às adquiridas na escola, podem propiciar novos conhecimentos a serem compartilhados dentro e fora dela, colaborando, portanto, para a demarcação de novas dicotomias e novos olhares sobre o outro (KUHN, 2008).

No ensino de língua inglesa, em particular, a internet pode propiciar aos alunos contato com diferentes comunidades linguísticas, de diferentes partes do mundo, e, por meio desse contato, propiciar condições para que eles agreguem novos conhecimentos sobre a língua à sua zona de desenvolvimento real (VIGOTSKY, 2001). Além disso, as formas de comportamento social dessas comunidades linguísticas estudadas, bem como sua cultura, arte e modos de significação, passam a ser contrastadas com as do aluno, fazendo assim com que ele tenha conhecimento da heterogeneidade característica da língua inglesa e dos saberes e culturas na qual a língua está inserida.

Aprender língua inglesa como língua estrangeira e saber utilizar novas tecnologias a favor da formação do cidadão tornaram-se características marcantes do atual contexto global de educação. Por outro lado, o ensino de língua inglesa no Brasil, embora tendo parâmetros curriculares que se comparam aos de grandes potências educacionais (Parâmetros Educacionais da União Europeia), ainda é arraigado nas tradicionais concepções de "escola como reprodutora de saberes”. Esse fato problematiza a notória não-relação entre a estrutura curricular educacional e a evolução das práticas pedagógicas no ensino de inglês nas últimas décadas. Isso aponta para a necessidade do questionamento de pressupostos que podem estar impedindo a evolução do processo de ensino de línguas estrangeiras no setor educacional brasileiro e a criação de novas metodologias de ensino que se adaptem à realidade econômica e social do país, caracterizada, como já dissemos, por um processo de hibridização cultural e linguístico (MENEZES DE SOUZA, 2004).

\section{APLICANDO AS NOVAS TECNOLOGIAS NA PRÁTICA DA INCLUSÃO SOCIAL}

Sabemos que, muitas vezes, os conhecimentos produzidos em esferas científicas refratam obliquamente durante a sua aplicabilidade nos mais variáveis contextos sociais. Isso não se deve apenas à falta de profissionais qualificados, mas muitas vezes à falta de iniciativa e de disposição em rever, recriar ou mesmo reanalisar o contexto educacional e a sua construção histórica (FOUCAULT, 2005). Obviamente, isso implica de forma direta a constante manutenção de velhos e tradicionais sistemas de ensino pautados na lógica tarefeira, produtivista e avaliativa da escola pública brasileira.

Apesar dos vastos incentivos governamentais para a inserção da informática na escola, 
como, por exemplo, o Projeto Escolas em Rede do Governo do Estado de Minas Gerais, a problemática maior no processo de informatização destas não reside na falta de verbas ou na aquisição de computadores. Pelo contrário, ela se dá na necessidade de professores, alunos, escola e sociedade se apropriarem de uma nova concepção de realidade escolar a partir da utilização das novas tecnologias no contexto educacional.

Na tentativa de refletirmos sobre as mais variadas formas de construir novos paradigmas educacionais acerca da utilização das novas tecnologias em sala de aula e a sua preponderância na construção de uma nova organização educacional, decidimos ir à escola pública em busca de possíveis mecanismos que tragam perspectivas transformacionais relacionadas à aplicabilidade do uso da internet e da língua inglesa às práxis sociais dos alunos.

Antes de começarmos nossas ações, foi necessário realizarmos um vasto levantamento bibliográfico para que, assim, o arcabouço teórico fosse delineando a direção que iríamos tomar no decorrer do trabalho. Posteriormente, selecionamos uma escola pública da cidade de UberlândiaMG, onde preparamos para a turma do nono ano do ensino fundamental, juntamente com a professora, aulas de inglês baseadas na utilização da internet, com o intuito de promover o senso de inclusão social dentro da concepção acima explicitada. Durante todo o processo de aplicação das aulas preparadas por nós, coletamos dados por meio de observações e questionários.

Investigar como o uso da internet poderia refletir na aprendizagem de língua inglesa e como esse processo poderia resultar na inclusão social dos alunos constituía o nosso objetivo maior de pesquisa. Para isso, inicialmente fizemos um levantamento de ferramentas multimodais disponíveis na web que pudessem ser usadas sem nenhuma dificuldade pelos professores de inglês dessa escola pública. Devido ao tempo de pesquisa disponível (seis semanas), escolhemos três ferramentas virtuais: Google, dictionary.com e YouTube. Feito isso, analisamos como essas ferramentas poderiam, por meio da prática dos letramentos e multiletramentos, levar os alunos a uma visão crítica de mundo enquanto construíam saberes (LANKSHEAR \& KNOBEL, 2003) a partir das aulas de inglês.

Como método de investigação, optamos pelo método qualitativo. Além disso, fundamentamos nossas investigações nos princípios etnográficos de Hammersley \& Atkinson (1983), objetivando resultados e comprovações de hipóteses.

\section{A INTERNET COMO FERRAMENTA DIDÁTICA PARA O LETRAMENTO EM LÍNGUA INGLESA}

A linguagem e a percepção estão diretamente ligadas (VIGOTSKY, 2001). A internet como uma ferramenta multimodal nos proporciona espaços ocupados por realidades e percepções humanas que podem ser dispostos na esfera da linguagem e armazenados na web da forma mais natural possível. Partindo dessa perspectiva, durante a elaboração das aulas que foram aplicadas aos alunos, procuramos utilizar instrumentos capazes de promover reflexões sobre a relação entre as práticas sociais e a linguagem.

As aulas foram ministradas no período letivo regular, levando-se em conta as temáticas dispostas de forma sequencial no livro didático e o plano de curso do professor. Dar continuidade ao conteúdo que já estava sendo ministrado foi essencial para provocar mudanças nas atitudes e nos olhares dos alunos frente à forma de aprender e ensinar a língua inglesa. 
Devido à necessidade de delimitarmos a escrita de nosso trabalho e de direcionarmos nossas explicações de modo a responder nossas perguntas de pesquisa, escolhemos duas aulas ministradas para serem aqui relatadas, sendo uma de conteúdo vocabular e outra de conteúdo gramatical. Esses conteúdos não foram escolhidos por acaso. A forma de ver a língua inglesa de maneira dicotômica, aberta em conteúdo gramatical e conteúdo vocabular, é geralmente uma premissa de muitos professores de inglês da educação pública (LIMA \& MASCIA, 2011). Assim, ao pensarmos em escrever aqui um "roteiro diferente de aula de inglês" a partir da internet, pensamos também na possibilidade de alcançar esses professores.

É fundamental ressaltar que as aulas foram planejadas pelo pesquisador que, com antecedência, apresentou e discutiu os planos de aula com a professora regular da turma pesquisada. Esta continuou a ministrar normalmente as aulas, porém, no laboratório de informática. Ao pesquisador coube apenas a tarefa de observar as aulas e colher dados com o auxílio de notas de campo.

\subsection{Aula de conteúdo vocabular}

A primeira aula proposta era de conteúdo vocabular e abordou a temática weather. Preparamos uma aula que empregasse ferramentas disponíveis na internet, sabendo de antemão da disponibilidade de um computador por aluno. Os recursos utilizados nesse primeiro momento foram o dicionário on-line dictionary.com e o Google, ambos disponíveis na internet. O dicionário tinha como objetivo suscitar nos alunos a curiosidade pela pronúncia e pelo significado das palavras dispostas na lista do novo vocabulário apresentado pelo livro didático, e o Google seria utilizado como instrumento de pesquisa. As pesquisas eram referentes às condições climáticas de algumas cidades e países e sua localização geográfica na esfera global.

Antes de pedir aos alunos que começassem a utilizar seus computadores, projetamos no telão do laboratório de informática algumas fotos características de algumas cidades, como, por exemplo, o Corcovado, representando a cidade do Rio de Janeiro. Ao projetarmos essas fotos, perguntas como "Where is it? What city is this? Where is Rio de Janeiro? Is it in the north or in the south? Have you been there? Is it violent? Is it beautiful? eram feitas, almejando despertar nos alunos o conhecimento da localização espacial e geográfica das cidades e as relações existentes entre localização e fatores climáticos. Além disso, alguns conceitos políticos municipais foram contrastados com os de outras cidades, na tentativa de instigar novos olhares sobre si por parte dos alunos.

A intenção de promover uma reflexão crítica sobre estereótipos e crenças presentes no senso comum da língua inglesa também foi explorada. Na figura abaixo, temos a reprodução de um slide utilizado na aula. Ao projetarmos a imagem semelhante à de um castelo, os alunos rapidamente afirmaram que a foto se tratava da Disney, entretanto a foto era da Catedral de São Basílio, Moscou, em primeiro plano, vendo-se ao fundo uma das torres do Kremlin, sede do governo russo. Aproveitamos esse momento para fazermos reflexões sobre a necessidade de visões críticas de mundo e expandirmos o conhecimento sobre diferentes regiões, a começar pelo bairro e pela cidade dos alunos. Enfocamos, a partir daí, que a internet poderia ser uma excelente ferramenta de pesquisa para abrir os olhos em relação a essas realidades. 


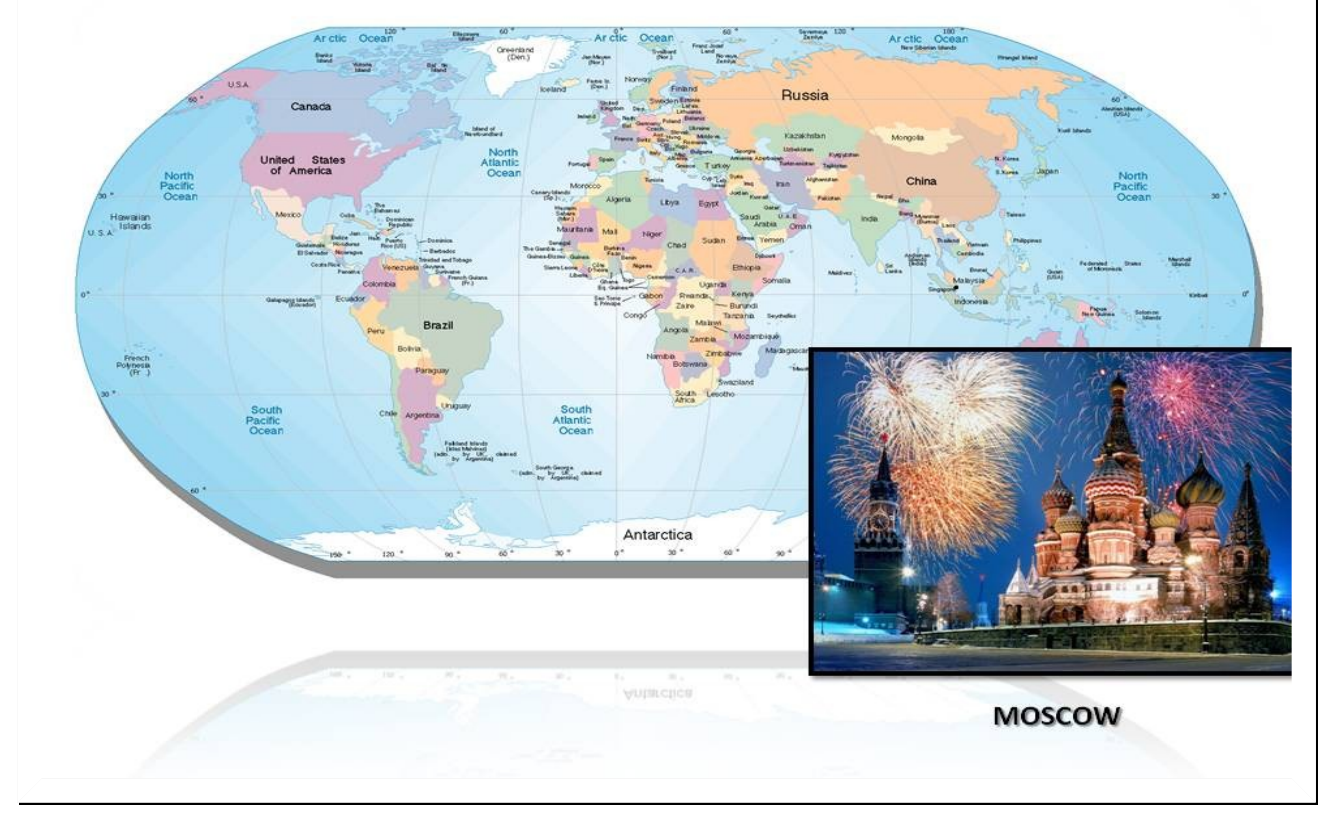

Figura 2: Slide 05 da primeira aula

Após instigarmos os alunos a refletirem sobre as cidades projetadas no telão, dividimos o grupo de 13 alunos em duplas e trios, dando liberdade para que eles abrissem a internet em seus computadores e pesquisassem informações, em páginas de língua inglesa, referentes ao clima da cidade proposta ao grupo. Para essa atividade foi estabelecido um prazo de 10 minutos.

Após debatermos as informações encontradas sobre as cidades, projetamos algumas palavras no telão e pedimos aos alunos que fossem ao dictionary.com. Antes de proceder à atividade, a professora explorou os recursos disponíveis no dicionário on-line e pediu aos alunos que escolhessem nove palavras do novo vocabulário do livro, treinassem a pronúncia e descrevessem seus significados em língua inglesa, tendo como suporte o dicionário on-line. Nesse momento os alunos ficaram muito curiosos, pois ainda não conheciam essa ferramenta virtual.

Apesar de observarmos alguns problemas com relação à utilização dos recursos disponíveis no laboratório de forma alheia à aula - como, por exemplo, o fato de alguns alunos terem se desviado da proposta feita pela professora, acessando sites de relacionamento como Facebook, ou e-mails pessoais - a experiência foi gratificante em termos de letramento e inclusão digital, pois eles tiveram acesso a informações sobre diferentes lugares e culturas, por intermédio do Google, e se despertaram para a necessidade de ampliar seus conhecimentos de mundo sobre esses lugares. O que mais nos chamou a atenção é que muitos alunos postaram sites e fotos relacionados às cidades e monumentos que apresentamos em sala de aula no Facebook. Isso pode ser um indicativo de que os tão condenados sites de relacionamento podem ser um campo muito grande a ser explorado nas escolas como uma ferramenta de inclusão social. 


\subsection{Aula de conteúdo gramatical}

O foco da terceira aula foi o tempo verbal Past Continuous. Com o intuito de retomar o vocabulário trabalhado nas aulas anteriores, selecionamos um filme de curta metragem disponível no YouTube, chamado Strangers, de Tadmor \& Nattiy (2004). Nesse filme, conflitos de identidades culturais e étnicas são claramente expostos na forma de um encontro acidental de dois passageiros em um trem em Paris, sendo um deles de origem judaica (a julgar pela estrela de Davi no colar em seu pescoço), e o outro de origem palestina (a julgar pelo jornal que estava lendo na viagem).

Para evitar dispersão por parte dos alunos, no que diz respeito às ferramentas on-line que não tinham conexão com a aula, montamos um telão no laboratório e o organizamos com todos os aparatos necessários à exibição. Dividimos o vídeo em três partes, pedindo a eles que assistissem à primeira parte e tentassem responder algumas perguntas relacionadas ao tempo e espaço em que se passava o filme. Na segunda parte, pedimos a eles que respondessem algumas perguntas sobre os acontecimentos narrados no filme. Aproveitamos essas perguntas para explicar a formação gramatical do Past Continuous e, em seguida, pedimos que os alunos dessem mais exemplos de uso desse tempo verbal. Por fim, pedimos a eles que dessem um desfecho para a história.

Durante a primeira e segunda partes do filme, os alunos ficaram bastante atentos a tudo o que acontecia na aula. Todas as perguntas que a professora fazia eram respondidas. Na segunda parte, os alunos se mantiveram bastante atentos e não tiveram problemas em responder às perguntas referentes à contextualização gramatical. Querendo saber o que estava por vir no final do filme, os alunos prestaram atenção às explicações gramaticais, e, mesmo havendo algumas dispersões, percebemos nesse momento que a internet - cabe aqui também o computador - como um instrumento de apoio provedor de materiais concretos midiáticos e multimodais embutidos de práxis sociais críticas, quando devidamente utilizado pelo professor em sala de aula, pode trazer resultados efetivos na explicitação do conhecimento gramatical da língua inglesa.

Na terceira parte, pedimos que os alunos dessem um desfecho para a história. Muitas opiniões emergiram e houve uma forte interação entre os colegas na tentativa de adivinhar o desfecho do filme. Após o término do vídeo, o filme foi exibido novamente, e os alunos foram convidados a falar sobre as diferenças raciais e étnicas e a importância de respeitarmos essas diferenças (em língua inglesa ou portuguesa). Esse momento foi interessante porque os alunos se sentiram à vontade para dar exemplos de suas próprias comunidades de prática (WENGER, 1998); por exemplo, muitos falaram sobre o bairro em que vivem.

As conclusões que podemos extrair dessa aula é que ela resultou na construção de um momento importante para desenvolver, a partir da internet, a inclusão social. Isso porque conseguimos estabelecer uma relação entre a práxis social dos alunos e o conteúdo abordado em sala de aula. Os alunos, de forma perceptível, começaram a prestar mais atenção à aula e a fazer comentários pertinentes aos assuntos abordados.

\section{CONSIDERAÇÕES FINAIS}

Como vimos anteriormente, a inclusão social pode se dar de várias maneiras e resultar de diversas ações. Sendo a escola uma instituição pluridisciplinar formada por diferentes áreas do conhecimento e com a função de facilitar a inclusão social de seus alunos, ela deve promover a 
construção do conhecimento em uma sociedade, fazendo com que essa relação se reflita no comportamento e nas ações do cidadão em seu convívio social. Dessa forma, ela passa a propiciar aos alunos o reconhecimento da heterogeneidade característica das linguagens, saberes e culturas do contexto social no qual estão inseridos. Tal reconhecimento pode desencadear o questionamento de verdades aceitas como fixas, únicas, estáveis, e o aparecimento de novos paradigmas educacionais e sociais.

Nas ultimas décadas, as novas tecnologias ganharam espaço no processo de ensino/aprendizagem de línguas, aproximando-o das exigências de constante atualização e modernização da sociedade atual. Entre essas exigências figuram o conhecimento de inglês como língua estrangeira e a capacidade de utilizar as novas tecnologias a favor da formação do cidadão.

Em meio às novas tecnologias aplicadas à educação, a internet exerce um papel fundamental no que diz respeito à pesquisa e à expansão do conhecimento construído na escola, colaborando, portanto, para o aparecimento de novos olhares sobre o outro. Como vimos, isso decorre do contato, pela internet, com diferentes comunidades linguísticas, de diferentes partes do mundo, contato que pode trazer a conscientização da heterogeneidade característica da língua inglesa e dos saberes e culturas nos quais a língua está inserida.

No decorrer da pesquisa, apesar de em diversos instantes percebermos a necessidade de evitar a dispersão dos alunos em aulas que utilizam a internet como recurso complementar, verificamos que é possível trabalhar utilizando essa ferramenta de forma a trazer novos olhares sobre o mundo e promover a inclusão social como a concebemos em nossa discussão inicial. Além disso, pensamos especialmente na necessidade de revermos o profissionalismo e a prática do professor de língua inglesa no ensino público.

Por fim, este trabalho foi motivado pela crença de que é possível educar em favor da inclusão social com o uso da internet, o que pôde ser observado nas aulas de inglês descritas neste trabalho e nas demais aulas propostas e realizadas por nós durante a pesquisa. Esperamos que, a partir deste trabalho, possamos contribuir para o surgimento de novas reflexões a respeito da utilização de ferramentas da internet no ensino de língua inglesa como um possível instrumento de inclusão social.

\section{REFERÊNCIAS}

COPE, B.; KALANTZIS, M. Multiliteracies: literacy learning and the design of social futures. London: AVA, 2003.

FOUCAULT, M. A Verdade e as Formas Jurídicas. 3. ed. Rio de Janeiro: NAU Editora, 2005.

FRIEDMAN, M. Capitalism and Freedom: Ideas on liberty by the 1976 Nobel Prize winner. New York: The Freeman Journal . vol. 27, n.1. Jan, 1977.

GRADDOL, D. English Next: Why global English May mean the end of "English as a Foreign Language”. Plymouth: The British Council, 2006.

HAMMERSLEY, M. \& ATKINSON, P. Ethnography principles in practice. London: Cambridge 
University Press, 1983.

KUHN, T.S. A estrutura das revoluções científicas. São Paulo: Perspectiva, 2008.

LANKSHEAR, C. \& KNOBEL, M. New Literacies, Changing Knowledge and Classroom Learning. London and New York: Open University Press, 2006.

LIMA, T. A. \& MASCIA, M. A. A. (Re)torcendo os fios do discurso político educacional da EaD: uma análise dos documentos do MEC. In: CORACINI, M. J. et AL (Orgs.). Da letra ao píxel e do pixel à letra: uma análise discursiva do e sobre o virtual: identidade, leitura e escrita, formação de professores e ensino-aprendizagem de línguas. Campinas, SP: Mercado de Letras, 2011. p. 261-283.

MENEZES DE SOUZA, L.M.T. Hibridismo e Tradução Cultural em Bhabha. In: ABDALA JUNIOR, B. Margens da Cultura: Mestiçagem, Hibridismo e Outras Misturas. Benjamin Abdala Junior, org. São Paulo: Boitempo, 2004.

MOITA LOPES, L.P. Inglês e Globalização em uma epistemologia de fronteira: Ideologia Lingüística para tempos híbridos. Rio de Janeiro: Delta, 2008.

MONTE MOR, W. \& MENEZES DE SOUZA, L. M. T. Orientações Curriculares para o Ensino Médio: Línguas Estrangeiras in Brasil. Linguagens, Códigos e suas Tecnologias. Brasília: MEC/SEB, 2006.

NOVA ESCOLA. $O$ que é indisciplina. Edição online. Disponível em:

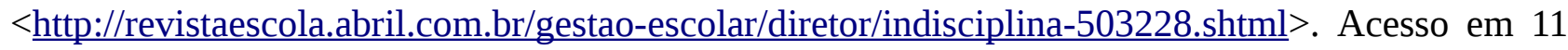
de jul. de 2013.

TADMOR, E. \& NATTIY, G. Strangers. Paris, 2004. Disponível em: <http://www.youtube.com/watch?v=RpjHSiQLPmA>. Acesso em 4 de fev. de 2013.

VICHESSI, B. Como se Livrar da Indisciplina. Educar Para Crescer [página de internet]. Editora Abril. 2009. Disponível em: <http://educarparacrescer.abril.com.br/comportamento/indisciplinasala-aula-509283.shtml>._Acesso em 30 de out. de 2009.

VIGOTSKY, L.S. A formação Social da Mente. São Paulo: Martins Fontes, 2001.

WENGER, E. Communities of practice: learning, meaning, and identity. Cambridge: Cambridge University Press, 1998. 
i Aqui fazemos uma referência à sociedade descrita por Foucault (2009) no livro Vigiar e Punir e às formas de poder exercido pelas classes dominantes sobre o Estado e pelo Estado ao seu povo. 